\title{
Rare 6-deoxy-D-altrose from the folk medicinal mushroom Lactarius akahatsu
}

\author{
Masakuni Tako ${ }^{1,2^{*}}$, Jyunpei Shimabukuro ${ }^{1,3}$, Wen Jiang ${ }^{1}$, Masashi Yamada ${ }^{3}$, Hideharu Ishida ${ }^{3}$ and Makoto Kiso ${ }^{3}$ \\ *Correspondence: tako@agr.u-ryukyu.ac.jp \\ 'University of the Ryukyus, Department of Subtropical Bioscience and Biotechnology, Nishihara, Okinawa 903-0213, Japan. \\ 'University of the Ryukyus, Health and Longevity Research Laboratory, Integrated Innovation Research Centre, Nishihara, Okinawa \\ 903-0213, Japan. \\ ${ }^{3}$ Gifu University, Department of Applied Bio-organic Chemistry, Gifu, Gifu 501-1193, Japan.
}

\begin{abstract}
A rare sugar, 6-deoxy-D-altrose, isolated from a polysaccharide extracted from an edible folk medicinal mushroom (Lactarius akahatsu) was identified using ${ }^{1} \mathrm{H}$ and ${ }^{13} \mathrm{C}-\mathrm{NMR}$ including 2D-COSY and 2D-HSQC spectroscopy, and specific rotation. The 6-deoxy-sugar isolated from the acid hydrolysate of the polysaccharide extracted from L. akahatsu was involved in four anomeric isomers ( $\alpha$ - and $\beta$-pyranose, and $\alpha$-and $\beta$-furanose) in aqueous solution due to mutarotation. Almost all of the signals from the $1 \mathrm{D}$ $\left({ }^{1} \mathrm{H}\right.$ - and ${ }^{13} \mathrm{C}$-) and 2D (COSY and HSQC)-NMR spectra of the 6-deoxy-sugar agreed with the data from the authentic 6-deoxy-Daltrose. The specific rotation $[\alpha]_{589}$ of the 6 -deoxy-sugar isolated from L. akahatsu was $+17.6^{0}$. Thus, the 6-deoxy-sugar isolated from Lactarius akahatsu was identified as 6-deoxy-D-altrose.
\end{abstract}

Keywords: Lactarius akahatsu, folk medicinal mushroom, 6-deoxy-D-altrose, rare sugar, polysaccharide moiety

\section{Introduction}

In proceeding studies, we isolated a novel acetyl fucoidan from commercially marine cultured Cladosiphon okamuranus $[1,2]$, and which has been patented [3]. The acetyl fucoidan has some biological activities, such as antitumor [4] and immuneenhancing [5]. Specifically, over-sulfated acetyl fucoidan, the sulfate content of which was $32.8 \%$, showed significant antitumor activity [4]. The results suggested that the oversulfated acetyl fucoidan was applicable to an anticancer drug.

The fruiting bodies of mushrooms have been used as foodstuffs and folk medicine throughout the world since ancient times, especially in Japan and China [6,7]. Many attempts have been made to explore the use of mushrooms and their metabolites for the treatment of various human ailments [8,9]. Certain polysaccharides ( $\beta$-glucans) from mushrooms have been applied as anti-tumor and immune-enhancing agents for clinical use in Japan $[7,10]$. Consequently, mushroom polysaccharides have drawn the attention of chemists and immune-biologists in recent years because they possess antitumor and immuneenhancing properties.

The fruiting bodies of a Lactarius lividatus (previously Lactarius hatsudake) have historical use as antitumor and antiviral agents in Japanese and Chinese folk medicine [11]. We identified a rare 6-deoxy-D-altrose from the mushroom, which is widespread in natural environments within South-East Asia, East Asia, North America, and Europe [12]. Our previous report detailed the first complete identification of a 6-deoxy-D-altrose in nature.

Furthermore, we have previously reported the structure of a novel polysaccharide, which was substituted with 6-deoxy$D$-altrose, isolated from L. lividatus [13]. The polysaccharide was highly branched 1,2- and 1,6-linked a-D-glucan, and its terminal residues were 6-deoxy- $\beta$-D-altropyranose and $a-D-$ galactopyranose. This report described the first identification of a rare 6-deoxy-D-altropyranose moiety on polysaccharides.

Lactarius akahatsu is widespread in natural environments throughout the world. In Okinawa Prefecture, Japan, its fruiting bodies have been eaten since ancient times alongside $L$. lividatus. The fruiting bodies of Lactarius akahatsu have also been used as folk medicine in Japan and China.

This paper describes identification of rare 6-deoxy-D-altrose from a polysaccharide isolated from L. akahatsu.

\section{Materials and methods}

The fresh fruiting bodies of $L$. akahatsu were collected in Onna Village, Okinawa, Japan in the February of 2009. The pilei of the fruiting bodies are $40-100 \mathrm{~mm}$ in diameter, and a light brownish orange in color. The lamellae and stipe are both orange. The fresh fruiting bodies were washed with distilled water and air dried at $40^{\circ} \mathrm{C}$ for $48 \mathrm{~h}$ before being ground into powder.

The fruiting bodies of $L$. akahatsu were suspended in ethanol (90\%) or acetone, and stirred for $3 \mathrm{~h}$ to extract the pigment or lipid, respectively. The sample $(20 \mathrm{~g})$ was suspended in distilled water and stirred at $90^{\circ} \mathrm{C}$ for $3 \mathrm{~h}$ to extract the polysaccharide. The extract was then centrifuged at $23000 \mathrm{~g}$ for $20 \mathrm{~min}$, and the supernatant was filtered through Celite 545 (Nakarai, Japan). The filtrate was precipitated by adding 2 volumes of ethanol, 
Tako et al. Biochemical Compounds 2013,

http://www.hoajonline.com/journals/pdf/2052-9341-1-5.pdf

doi: 10.7243/2052-9341-1-5

and the resulting solid was dried in vacuo [12].

The crude polysaccharide was dissolved in distilled water and $10 \%$ trichloroacetic acid was added to precipitate any protein. The solution was passed through Celite 545 and dialyzed at $4^{\circ} \mathrm{C}$ for 3 days. The dialysate was deionized by passage through a cation exchange column composed of Amberlite $120 \mathrm{~A} \mathrm{H}^{+}$(Organo, Japan). The solution was dialyzed against distilled water for $24 \mathrm{~h}$ at room temperature and subsequently lyophilized [12].

\section{Synthesis of the authentic 6-deoxy-D-altrose}

The authentic 6-deoxy-D-altrose was synthesized from D-mannose via the D-rhamnoside [14]. The selective 3-O-benzylation of the D-rhamnoside was accomplished using stannylation, in which an unprotected starting material was activated with dibutyltin oxide, benzylated in the presence of benzyl bromide and tetrabutylammonium iodide, and finally acetylated to afford the 3-O-benzylated derivative in $79 \%$ yield over two steps. The deprotection of benzyl group, which occurred without acetyl group migration, was accomplished in $98 \%$ yield by hydrogenolysis over palladium on carbon at atmospheric pressure. Next, the triflation was achieved using triflic anhydride and pyridine in dichloromethane to give the triflate, which was treated with tetrabutylammonium acetate in toluene to afford the expected 6-deoxy-D-altropyranoside in $71 \%$ over two steps. The ${ }^{1} \mathrm{H}$ NMR data of the compound confirmed that the desired structure with the signal at 5.17 (dd, $1 \mathrm{~Hz}, J_{2,3}=2.0 \mathrm{~Hz}, J_{3,4}=3.5 \mathrm{~Hz}, \mathrm{H}-3$ ) was synthesized. A dramatic change in the $J_{3,4}$ value from $9.6 \mathrm{~Hz}$ to $3.5 \mathrm{~Hz}$ indicated that the inversion of configuration had occurred at $\mathrm{C}$-3. The oxidative removal of the $p$-methoxyphenyl group of the per-O-acetylated 6-deoxy-D-altropyranoside with ceric ammonium nitrate (CAN) afforded the hemiacetal in $68 \%$ yield, which was tentatively protected with a tetrahydropyranyl (THP) group to avoid any side reactions that may occur under the basic conditions in the next reaction. The removal of the acetyl groups under Zemplen conditions with subsequent acid hydrolysis of the THP group provided the desired free 6-deoxy-D-altrose in $78 \%$ over two steps.

\section{Chemical procedures}

The total carbohydrate content was determined with the phenol-sulfuric acid method using D-glucose as a standard [15]. The purified polysaccharide $(70 \mathrm{mg})$ was dissolved in distilled water $(20 \mathrm{~mL})$ and sulfuric acid was added to reach a final concentration of $1.0 \mathrm{~m}$. The mixture was subsequently heated to $100^{\circ} \mathrm{C}$ for $3 \mathrm{~h}$. The hydrolysate was neutralized with $\mathrm{BaCO}_{3}$.

Ascending paper chromatography of the acid hydrolysate from the polysaccharide, as well as authentic D-glucose, D-galactose, D-mannose, D-xylose, L-arabinose, L-fucose, and L-rhamnose, was performed on filter paper (No. 50; Advantec, Japan) using an eluent composed of butanol-ethanol-water (4:1:5, by volumes). Spots composed of reducing sugars were stained by spraying with the aniline hydrogen phthalate reagent and subsequent heating at $105^{\circ} \mathrm{C}$ for $4 \mathrm{~min}$.

The unknown sugar was separated by paper chromatography (Advantec Filter Paper No. 50; butanol-ethanol-water=4:1:5 as solvent). The band attributed to the unknown sugar (Spot 1: Rf 0.41) was cut off and extracted with distilled water at $4^{\circ} \mathrm{C}$ for $24 \mathrm{~h}$. The extract was concentrated and freeze-dried.

Optical rotation was measured at $589 \mathrm{~nm}$ on a polarimeter (P-1100, Japan Spectroscopic Co., Ltd., Japan) for 0.2\% (W/V) of polysaccharide, 6 -deoxy-sugar (0.13\%) and authentic 6-deoxy-D-altrose $(0.11 \%)$ in distilled water at $25^{\circ} \mathrm{C}$.

High-performance anion exchange chromatography coupled with the pulse amperometric detector (HPAECPAD)

The monosaccharides in the hydrolysate of the polysaccharide were identified using a HPAEC (DX-500, Dionex Co., CA, USA), fitted with Carbopack PA1 column and a pulsed amperometric detector. The column was eluted at flow rate of $1 \mathrm{~mL} / \mathrm{min}$ at $35^{\circ} \mathrm{C}$ with $10 \mathrm{mM} \mathrm{NaOH}$.

\section{${ }^{1} \mathrm{H}$-and ${ }^{13} \mathrm{C}$-Nulear magnetic resonance (NMR) spectro- scopy}

${ }^{1} \mathrm{H}$ - and ${ }^{13} \mathrm{C}-\mathrm{NMR}$ spectra were recorded on a FT-NMR spectrometer (AVANCE III 500 MHz, Bruker, Co., Ltd, Germany) at 500.00 and $125.65 \mathrm{MHz}$, respectively. The monosaccharide $(2.0 \%, W / V)$, from the sample and the authentic 6-deoxy-Daltrose, as well as the polysaccharide (2\%) were dissolved in $\mathrm{D}_{2} \mathrm{O}$ and recorded at $25^{\circ} \mathrm{C}$ for the monosaccharide and at $70^{\circ} \mathrm{C}$ for polysaccharide. The ${ }^{1} \mathrm{H}$-and ${ }^{13} \mathrm{C}-\mathrm{NMR}$ chemical shifts were expressed in parts per million (ppm) relative to sodium 3-(trimethylsilyl) propionic-2,2,3,3-d4 acid (TSP, $0.00 \mathrm{ppm}$ ) as an internal standard. Two-dimensional spectra of ${ }^{1} \mathrm{H}-{ }^{-1} \mathrm{H}$ COSY and ${ }^{1} \mathrm{H}-{ }^{13} \mathrm{C}$ heteronuclear single quantum coherence (HSQC) were recorded using standard Bruker procedures $[12,13]$.

\section{Results and discussion}

The isolated yield of the polysaccharide was estimated to be $1.3 \%(n=5)$, based on the dried weight. The polysaccharide contained $93.5 \%$ (W/W) of carbohydrate. The specific rotation $[\boldsymbol{\alpha}]_{589}$ of the polysaccharide $(0.2 \%, \mathrm{~W} / \mathrm{V})$ was $+23.8^{\circ}$, indicating that the a-configurations are predominated. Using high performance anion-exchange chromatography coupled with a pulse amperometric detector (HPAEC-PAD) to separate the hydrolysate of the polysaccharide, not shown in Figure, D-glalactose and D-glucose were identified in a molar ratio 1.0:3.0.

The ${ }^{1} \mathrm{H}-\mathrm{NMR}$ spectrum of the polysaccharide collected at $500 \mathrm{MHz}$ was shown in (Figure 1A). The four signals were observed in the anomeric region ( $\boldsymbol{\delta} 5.5-4.5)$ at 5.387, 5.119, 5.023 and $5.004 \mathrm{ppm}$, respectively. In addition, a major signal at 1.331 and 1.320 ppm was also observed, indicating that a 6-deoxy-sugar was integrated into the polysaccharide.

The ${ }^{13} \mathrm{C}$-NMR spectrum of the polysaccharide was shown 
Tako et al. Biochemical Compounds 2013,
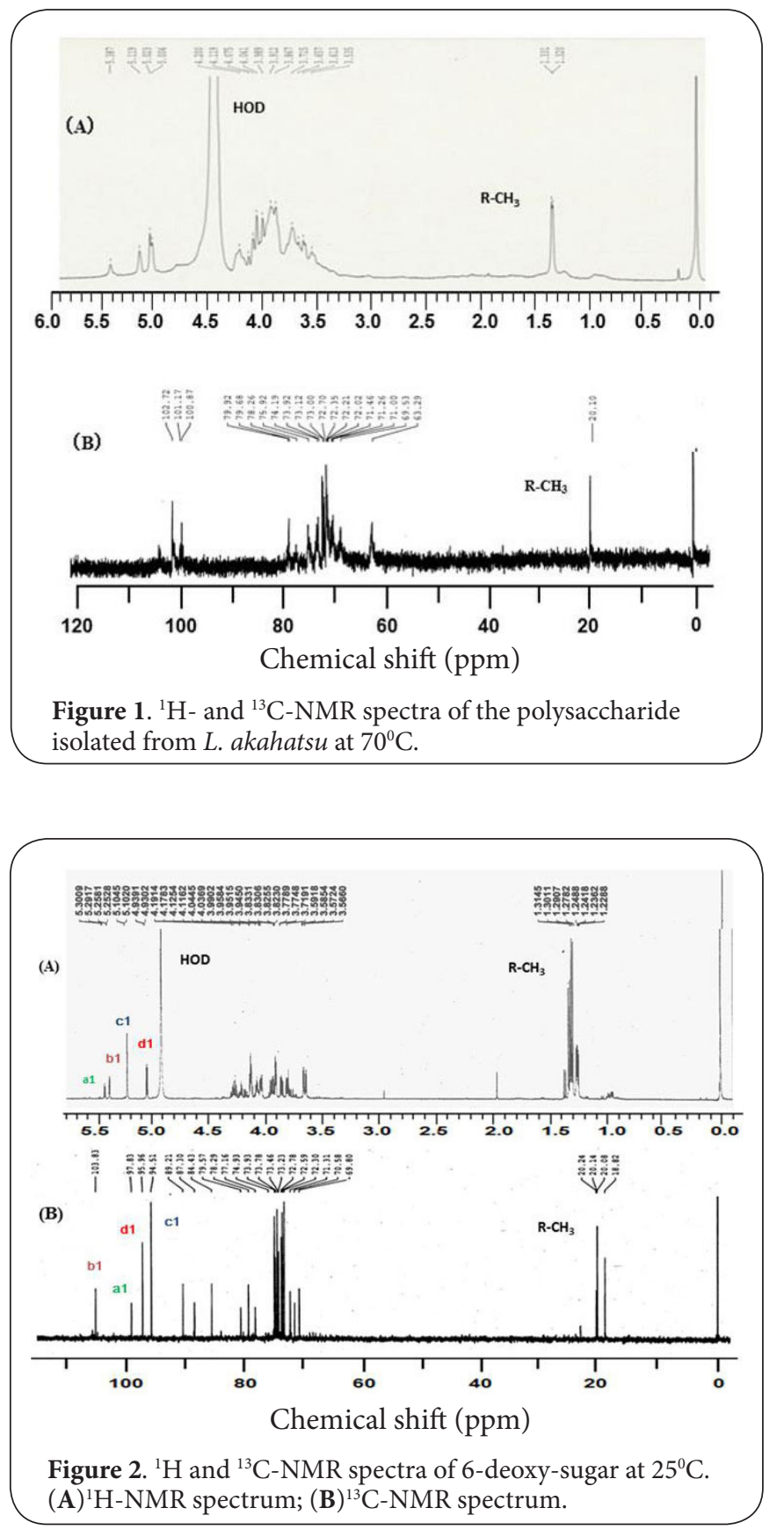

in (Figure 1B). The three anomeric signals were observed at $103.17,101.68$, and $101.32 \mathrm{ppm}$, respectively. A methyl signal at $20.54 \mathrm{ppm}$ was observed, indicating that a 6-deoxy-sugar was part of the polysaccharide.

Although the HPAEC-PAD data suggested that the polysaccharide consisted only of D-galactose and D-glusoe, an unknown 6-deoxy-sugar, which would have overlapped with the peak of D-galactose or D-glucose in the HPAEC-PAD data, was detected in the ${ }^{1} \mathrm{H}$ - and ${ }^{13} \mathrm{C}-\mathrm{NMR}$ spectra. These results agreed with the data from the polysaccharide isolated from L. lividatus [12].
Paper chromatography of the acid hydrolysate of the polysaccharide was conducted and is displayed in (Supplement figure S1). Spot 1 (Rf, 0.41) was higher than the spot attributed to the standard L-rhamnosyl residue (0.37). Alhough D-glucose and D-galactose were detected with HPAEC$P A D$, both sugars overlapped on the paper chromatogram (spot 2 and 3).

Using paper chromatography on a preparative scale, 6-deoxy-sugar (spot 1) was isolated from the mixture obtained by hydrolyzing the polysaccharide with acid and extracting the product with distilled water.

The ${ }^{1} \mathrm{H}$-NMR of the isolated 6-deoxy-sugar was presented in (Figure 2A). As reported previously [12], the 6-deoxy-D-altrose existed in aqueous solution as a mixture of the $a$ and $\beta$ conformers of the pyranose and furanose forms. This phenomenon was also observed with 6-deoxy-L-altrose [16]. The spectrum of the 6-deoxy-sugar (Figure 2A) indicated four forms were present (a, b, c and d signals for $\mathrm{H}-1$ at 5.3009 and 5.2917, 5.2581 and 5.2581, 5.1045 and 5.1020, and 4.9391 and 4.9302 ppm; for $\mathrm{H}-6$ at 1.3145 and $1.3011,1.2907$ and $1.2782,1.2488$ and 1.2418 , and 1.2326 and 1.2283 ppm, respectively). All of the signals agreed with the data collected from the authentic 6-deoxy-D-altrose, (not shown), as well as the sample of the 6-deoxy-D-altrose isolated from L. lividatus, previously reported [12].

The ${ }^{13} \mathrm{C}$-NMR spectrum of the 6-deoxy-sugar (Figure 2B) indicated the presence of four forms (signals for $\mathrm{C}-1$ at 103.83 , $97.83,95.96$, and 94.5 ppm, respectively; for C- 6 at 20.24, 20.14, 20.01 and $18.82 \mathrm{ppm}$, respectively). All of the signals ( $\mathrm{H}-1-\mathrm{H}-6)$ for the 6-deoxy-sugar agreed with the data collected from the authentic 6-deoxy-D-altrose, (not shown), as well as the 6-deoxy-D-altrose isolated from $L$. lividatus.

The 2D COSY spectrum of the 6-deoxy-sugar was shown in (Figure 3). From the Figure, it was possible to correlate $\mathrm{H}-1$ of a $(\delta 5.29)$ with $\mathrm{H}-2(\delta 4.07), \mathrm{H}-2$ with $\mathrm{H}-3(\delta 4.18), \mathrm{H}-3$ with $\mathrm{H}-4$ $(\delta 3.71), \mathrm{H}-4$ with $\mathrm{H}-5(\delta 3.94)$ and $\mathrm{H}-5$ with $\mathrm{H}-6(\delta 1.22) ; \mathrm{H}-1$ of b ( $\delta 5.24)$ with $\mathrm{H}-2(\delta 4.01), \mathrm{H}-2$ with $\mathrm{H}-3(\delta 4.09), \mathrm{H}-3$ with $\mathrm{H}-4$ $(\delta 3.76), \mathrm{H}-4$ with $\mathrm{H}-5(\delta 3.95)$ and $\mathrm{H}-5$ with $\mathrm{H}-6(\delta 1.24) ; \mathrm{H}-1$ of $c(\delta 5.08)$ with $\mathrm{H}-2(\delta 3.80), \mathrm{H}-2$ with $\mathrm{H}-3(\delta 4.03), \mathrm{H}-3$ with $\mathrm{H}-4$ $(\delta 3.56), \mathrm{H}-4$ with $\mathrm{H}-5(\delta 3.84)$ and $\mathrm{H}-5$ with $\mathrm{H}-6(\delta 1.26) ; \mathrm{H}-1$ of $\mathrm{d}(\delta 4.91)$ with $\mathrm{H}-2(\delta 3.75), \mathrm{H}-2$ with $\mathrm{H}-3(\delta 3.94), \mathrm{H}-3$ with $\mathrm{H}-4(\delta 3.70), \mathrm{H}-4$ with $\mathrm{H}-5(\delta 4.14)$ and $\mathrm{H}-5$ with $\mathrm{H}-6$ ( $\delta 1.31)$. Almost all of the signals for the 6-deoxy-sugar agreed with the data from the authentic 6-deoxy-D-altrose and the 6-deoxyD-altrose from L. lividatus [12]. The coupling constants for the 6-deoxy-sugar that were determined from COSY experiment were summarized in (Table 1). Almost all of the coupling constants for the 6-deoxy-sugar were identical with those of the authentic, (Supplement figure S2) and the 6-deoxy-Daltrose from L. lividatus. The results of the COSY experiment and the analysis of the HSQC spectrum (Figure 4) helped to assign residue a of the C-1, C-2, C-3, C-4, C-5 and C- 6 peaks in the 6-deoxy-sugar to $\delta 95.4, \delta 77.0, \delta 74.2, \delta 84.6, \delta 68.1$ and $\delta 20.2$ ppm, respectively. The other residues ( $b, c$ and $d$ ) were 
Tako et al. Biochemical Compounds 2013,

http://www.hoajonline.com/journals/pdf/2052-9341-1-5.pdf

doi: $10.7243 / 2052-9341-1-5$

Table 1. ${ }^{1} \mathrm{H}$ and ${ }^{13} \mathrm{C}$ NMR data for mutarotating 6-deoxy-D-altrose from L. akahatsu.

\begin{tabular}{|c|c|c|c|c|c|c|c|c|c|c|c|c|c|}
\hline Sample & & & & & & & & & & & & & \\
\hline 6-Deoxy-sugar & & $\mathrm{C}-1$ & $\mathrm{C}-2$ & $\mathrm{C}-3$ & C- 4 & C-5 & C-6 & $\mathrm{H}-1$ & $\mathrm{H}-2$ & $\mathrm{H}-3$ & $\mathrm{H}-4$ & H-5 & $\mathrm{H}-6$ \\
\hline \multirow[t]{2}{*}{ 6-Deoxy-D-alt $p(d)^{a}$} & a & 95.0 & 71.0 & 69.9 & 70.3 & 68.5 & 16.1 & 4.91 & 3.75 & 3.94 & 3.70 & 4.14 & 1.31 \\
\hline & $24.7^{\mathrm{b}} \%$ & -- & -- & -- & -- & -- & -- & -- & $J_{1,2}=4.1$ & $J_{2,3}=6.2$ & $J_{3,4}=3.2$ & $J_{4,5}=6.2$ & $J_{5,6}=6.2$ \\
\hline \multirow[t]{2}{*}{ 6-Deoxy-D-alt $p(c)^{a}$} & $\mathrm{~b}$ & 91.6 & 70.9 & 75.5 & 72.11 & 72.56 & 19.97 & 5.08 & 3.80 & 4.03 & 3.56 & 3.84 & 1.26 \\
\hline & $49.1^{\mathrm{b}} \%$ & -- & -- & -- & -- & -- & -- & -- & $J_{1,2}=1.1$ & $J_{2,3}=3.4$ & $J_{3,4}=3.2$ & $J_{4,5}=8.8$ & $J_{5,6}=6.3$ \\
\hline \multirow[t]{2}{*}{ 6-Deoxy-D-alt $f(b)^{a}$} & a & 101.3 & 81.8 & 75.5 & 86.4 & 67.0 & 17.3 & 5.24 & 4.01 & 4.09 & 3.76 & 3.95 & 1.24 \\
\hline & $16.8^{\mathrm{b} \%}$ & -- & -- & -- & -- & -- & -- & -- & $J_{1,2}=2.7$ & $J_{2,3}=4.0$ & $J_{3,4}=5.3$ & $J_{4,5}=5.2$ & $J_{5,6}=6.2$ \\
\hline \multirow[t]{2}{*}{ 6-Deoxy-D-akt $f(a)^{a}$} & $\mathrm{~b}$ & 95.4 & 77.0 & 74.2 & 84.6 & 68.1 & 20.2 & 5.29 & 4.07 & 4.18 & 3.71 & 3.94 & 1.22 \\
\hline & $9.4^{\mathrm{b} \%}$ & -- & -- & -- & -- & -- & -- & -- & $J_{1,2}=4.3$ & $J_{2,3}=7.0$ & $J_{3,4}=5.8$ & $J_{4,5}=7.9$ & $J_{5,6}=6.5$ \\
\hline
\end{tabular}

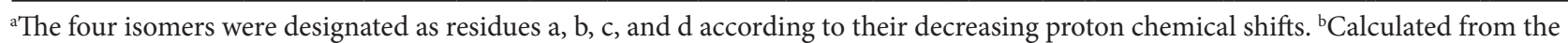
height of signals of the anomeric protons in Figure $\mathbf{2}$.

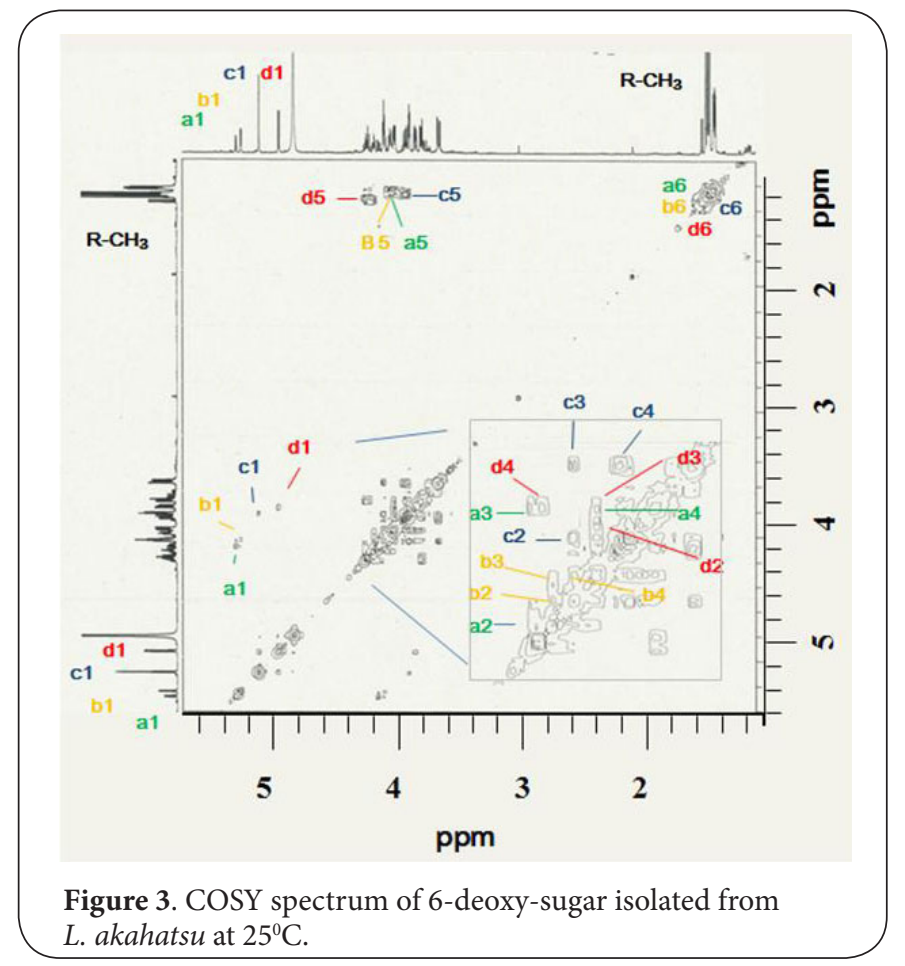

also assigned by a similar procedure and summarized in Table 1 . Almost all of the signals of the 6-deoxy-sugar agreed with the signals of the authentic 6-deoxy-D-altrose, (Supplement figure S3), and the 6-deoxy-D-altrose isolated from $L$. lividatus [12]. Therefore, from the results, the 6-deoxysugar isolated from L. akahatsu was identified as 6-deoxy- D or L-altrose.

The specific rotation of the 6-deoxy- $D$ or L-altrose isolated from $L$. akahatsu was estimated to be $+17.6^{\circ}\left(0.13 \%\right.$, at $25^{\circ} \mathrm{C}$ in $\mathrm{H}_{2} \mathrm{O}$ ). The values for the chemically synthesized authentic sample, as well as the material isolated from L. lividatus, were

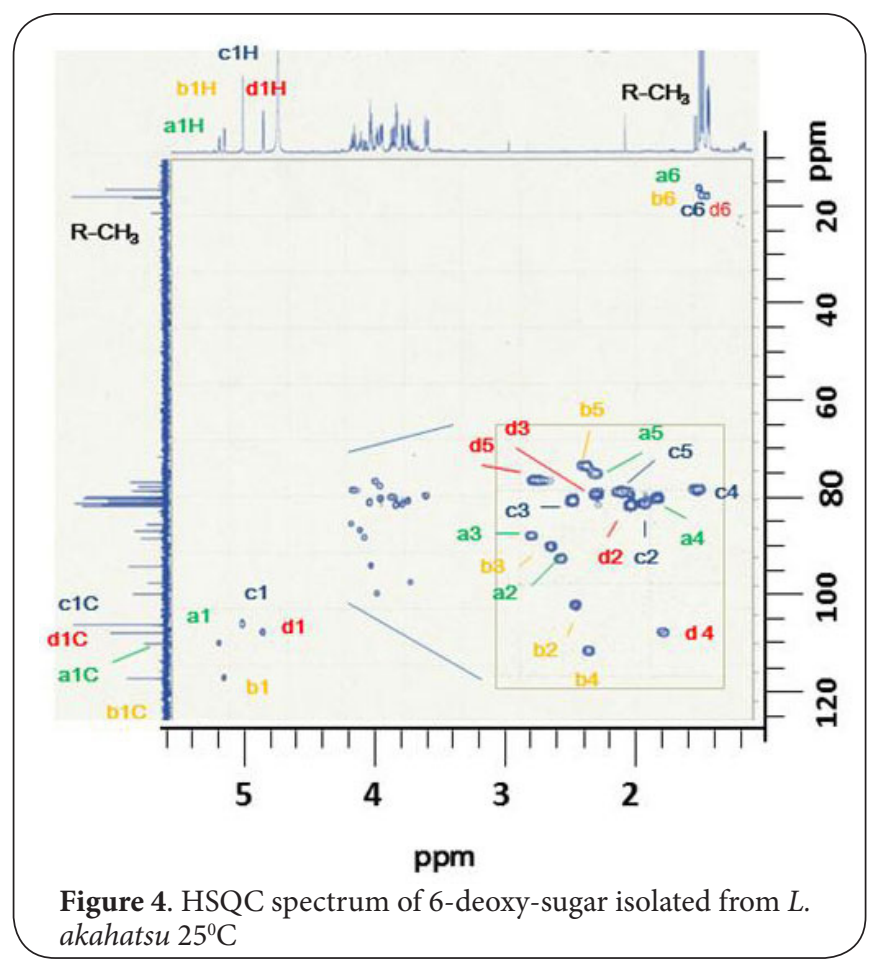

$+18.4^{\circ}\left(0.13 \%\right.$, at $\left.25^{\circ} \mathrm{C}\right)$ and $+18.2^{\circ}(0.11 \%)$, respectively. The specific rotation of the 6-deoxy-L-altrose has been reported as a negative value [17-19]. Therefore, this result indicates that the 6-deoxy-sugar isolated from L. akahatsus was identified as 6-deoxy-D-altrose.

\section{Conclusions}

In conclusion, by combining the results obtained in the current study with the data from a previous paper [12], four isomers of 6-deoxy-D-altrose (a, b, c and d) were identified as 6-deoxy- $\beta$-D-furanose (9.4\%), 6-deoxy- $\alpha$-D-furanose (16.8\%), 
Tako et al. Biochemical Compounds 2013,

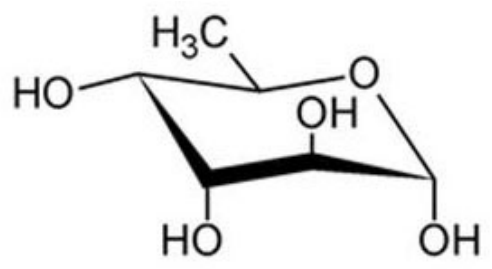

1. 6-Deoxy-a-D-altropyranose $(24.6 \%)$

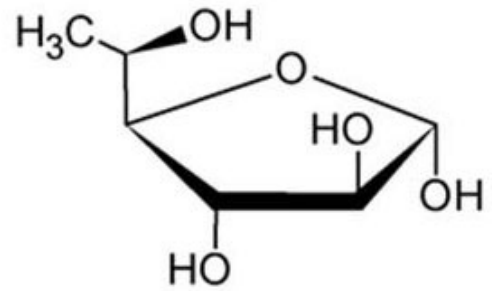

1. 6-Deoxy- $\alpha$-D-altropyranose

$(16.8 \%)$

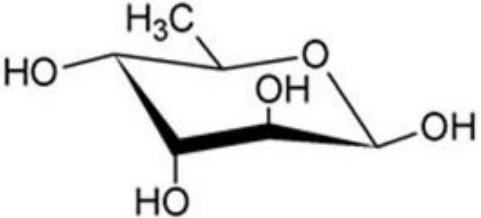

1. 6-Deoxy- $\beta$-D-altropyranose (49.1\%)

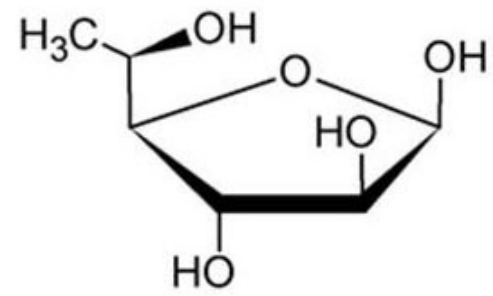

1. 6-Deoxy- $\beta$-D-altropyranose (9.4\%)

Figure 5. Chemical structure of 6-deoxy-D-altropyranoses and -altrofuranoses.

6-deoxy- $\beta$-D-pyranose (49.1\%) and 6-deoxy- $\alpha$-D-altropyranose $(24.6 \%)$ residue, respectively, as presented in (Figure 5). The signals for the 6-deoxy- $\alpha$ - and $\beta$-altropyranosyl residues were significantly more intense than the corresponding signals of $a$-and $\beta$-altrofuranosyl residues (Figure 2).

Finally, (Supplement figure S1) indicates that a large amount of the rare sugar, 6-deoxy-D-altrose, is available for isolation from the hydrolysate of the polysaccharide extracted from the fruiting bodies of L. akahatsu and L. lividatus [12]. Structural and biological investigations of the 6-deoxy-D-altrose and the polysaccharide from L. akahatsu are current in progress.

\section{Additional files}

\section{Supplement figure S1 Supplement figure S2 Supplement figure S3}

\section{Competing interests}

The authors declare that they have no competing interests.

\section{Authors' contributions}

\begin{tabular}{|l|c|c|c|c|c|c|}
\hline Authors' contributions & MT & JS & WJ & MY & HI & MK \\
\hline Research concept and design & $\checkmark$ & -- & -- & -- & $\checkmark$ & $\checkmark$ \\
\hline Collection and/or assembly of data & $\checkmark$ & $\checkmark$ & $\checkmark$ & $\checkmark$ & -- & -- \\
\hline Data analysis and interpretation & $\checkmark$ & -- & -- & -- & $\checkmark$ & $\checkmark$ \\
\hline Writing the article & $\checkmark$ & -- & -- & -- & -- & -- \\
\hline Critical revision of the article & $\checkmark$ & -- & -- & -- & -- & -- \\
\hline Final approval of article & $\checkmark$ & -- & -- & -- & -- & -- \\
\hline Statistical analysis & $\checkmark$ & -- & -- & -- & -- & -- \\
\hline
\end{tabular}

\section{Publication history}

Senior Editor: Vinod Kumar Tiwari, Banaras Hindu University, India. Editor: Butnariu Monica, Banat's University of Agricultural Sciences and Veterinary Medicine, Romanian.

Received: 25-Sep-2013 Revised: 06-Oct-2013

Re-Revised: 21-Oct-2013 Accepted: 22-Oct-2013

Published: $30-$ Oct-2013

\section{References}

1. Tako $M$, Uehara $M$, Kawashima $Y$, Chinen I and Hongou F. Isolation and identification of fucoidan from Cladosiphon okamuranus. J. Appl. Glycosci. 1996; 43:141-148.

2. Tako M, Yoza E and Tohma S. Chemical characterization of acetyl fucoidan and alginate from commercially cultured Cladosiphon okamuranus. Botanica Marina. 2000; 43:393-398. | Article

3. Tako $M$. The acetyl fucoidan and its manufacturing methods from commercially cultured Cladosiphon okamuranus. Japanese Patent 3371124, 2002.

4. Teruya T, Konishi T, Uechi S, Tamaki H and Tako M. Anti-proliferative activity of oversulfated fucoidan from commercially cultured Cladosiphon okamuranus TOKIDA in U937 cells. Int J Biol Macromol. 2007; 41:221-226. | Article | PubMed

5. Teruya $\mathrm{T}$, Tatemoto $\mathrm{H}$, Konishi $\mathrm{T}$ and Tako $\mathrm{M}$. Structural characteristics and in vitro macrophage activation of acetyl fucoidan from Cladosiphon okamuranus. Glycoconj J. 2009; 26:1019-1028. | Article | PubMed

6. Wasser S.P. Medicinal mushrooms as a source of antitumor and Immune-modulating polysaccharides. Appl. Micobiol. Biotechnol. 2002; 60:258-274.

7. Zhang M, Cui S.W, Cheung P.C.K and Wang Q. Antitumor polysaccharides from mushrooms: a review on their isolation process, structural characteristics and antitumor activity. Trends Food Sci. Technol. 2007; 18:4-19. | Article

8. Chihara G, Maeda Y, Hamuro J, Sasaki T and Fukuoka F. Inhibition of mouse sarcoma 180 by polysaccharides from Lentinus edodes (Berk.) Sing. Nature. 1969; 222:687-688. | Article | PubMed

9. Maeda YY and Chihara G. Lentinan, a new immuno-accelerator of cell- 
Tako et al. Biochemical Compounds 2013,

mediated responses. Nature. 1971; 229:634-647. | Article | PubMed

10. Chihara G. Immunopharmacology of lentinan, a polysaccharide isolated from Lentinus edodes: its application as a host defense potentiator. Int. J. Oriental Medicine. 1992; 17:57-77.

11. Gao JM, Wang M, Liu LP, Wei GH, Zhang AL, Draghici C and Konishi Y. Ergosterol peroxides as phospholipase $A(2)$ inhibitors from the fungus Lactarius hatsudake. Phytomedicine. 2007; 14:821-824. | Article | PubMed

12. Tako $\mathrm{M}$, Dobashi Y, Tamaki Y, Konishi T, Yamada $\mathrm{M}$, Ishida $\mathrm{H}$ and Kiso $M$. Identification of rare 6-deoxy-D-altrose from an edible mushroom (Lactarius lividatus). Carbohydr Res. 2012; 350:25-30. | Article I PubMed

13. Tako M, Dobashi Y, Shimabukuro J, Yogi T, Uechi K, Tamaki Y and Konishi T. Structure of a novel alpha-glucan substitute with the rare 6-deoxyD-altrose from Lactarius lividatus (mushroom). Carbohydr Polym. 2013; 92:2135-2140. | Article | PubMed

14. Yamada $M$, Yoshida F, Ando H, Ishida $H$, Kiso $M$ and Tako M. Synthesis of 6-deoxy-D-altrose used as an authentic sample to identify as unknown monosaccharide isolated from the fruiting body of an edible mushroom. Heterocycles. 2011; 82:1699-1704.

15. Dubois M, Gilles K.A, Hamilton J.K, Rebers P.A and Smith F. Colorimetric method for determination of sugars and related substances. Anal. Chem. 1956; 28:350-356. | Article

16. Hanniffy OM, Shashkov AS, Moran AP, Prendergast MM, Senchenkova SN, Knirel YA and Savage AV. Chemical structure of a polysaccharide from Campylobacter jejuni 176.83 (serotype 0:41) containing only furanose sugars. Carbohydr Res. 1999; 319:124-132. | Article | PubMed

17. Hoffman J, Lindberg B and Brubaker RR. Structural studies of the O-specific side-chains of the lipopolysaccharide from Yersinia enterocolitica Ye 128. Carbohydr Res. 1980; 78:212-214. | Article | PubMed

18. Gorshkova RP, Kalmykova EN, Isakov VV and Ovodov YS. Structural studies on O-specific polysaccharides of lipopolysaccharides from Yersinia enterocolitica serovars 0:1,2a,3, 0:2a,2b,3 and 0:3. Eur J Biochem. 1985; 150:527-531. | Article | PubMed

19. Senchenkova SN, Shashkov AS, Moran AP, Helander IM and Knirel YA. Structures of the O-specific polysaccharide chains of Pectinatus cerevisiiphilus and Pectinatus frisingensis lipopolysaccharides. Eur J Biochem. 1995; 232:552-557. | Article | PubMed

\section{Citation:}

Tako M, Shimabukuro J, Jiang W, Yamada M, Ishida $H$ and Kiso M. Rare 6-deoxy-D-altrose from the folk medicinal mushroom Lactarius akahatsu. Bio Chem Comp. 2013; 1:5. http://dx.doi.org/10.7243/2052-9341-1-5 